\title{
PLETHYSMOGRAPHIC DETERMINATION OF THE VOLUME OF GAS TRAPPED IN THE LUNGS ${ }^{1}$
}

\author{
By GEORGE N. BEDELL, 2 ROBERT MARSHALL, ${ }^{3}$ ARTHUR B. DuBOIS,4 AND \\ JULIUS H. COMROE, JR.
}

(From the Department of Physiology and Pharmacology, Graduate School of Medicine, University of Pennsylvania, Philadelphia, Pa.)

(Submitted for publication January 3, 1956; accepted January 30, 1956)

DuBois, Botelho, Bedell, Marshall, and Comroe have described a practical method, utilizing a body plethysmograph (1), for measuring the volume of compressible gas within the thorax; the method is a physical one which depends upon Boyle's law relating pressure and volume of a gas. It differs from all of the dilution and decompression methods in that it measures the volume of all gas in the thorax whether in communication with the airway or not, whereas the dilution and decompression methods measure only that volume of gas which is in communication with the airway during the period of the test. The dilution method measures only the volume which is ventilated over a specified period of time where "ventilation" is defined as the mass flow of gas in and out of the lungs. In normal individuals, the various methods yield approximately the same value. However, in patients with gas trapped in the lungs or pleural cavity, the thoracic gas volume measured plethysmographically should exceed that measured by the other methods and the difference in volumes should be the volume of trapped gas.

This expectation has been tested and realized in this study. The new approach has provided a means for determining the existence of gas which is trapped. The 'volume of trapped gas' is here defined as that component of thoracic gas volume which, having entered the thorax, is present in the lungs or pleural space but is unable to leave owing to intrapulmonary mechanical factors which prevent gaseous outflow. This method measures the volume of trapped gas and provides a means for

1 This investigation was supported (in part) by a research grant (H-406) from the National Heart Institute of the National Institutes of Health, Public Health Service.

2 U.S.P.H.S. Special Research Fellow; Present address : State University of Iowa, Iowa City, Iowa.

${ }^{8}$ Present address: The Dunn Laboratories, St. Bartholomew's Hospital, London, England.

4 Established Investigator, American Heart Association. extending our knowledge of the physiopathology of this phenomenon.

\section{PATIENTS AND METHODS}

A total of 36 patients has been studied; ${ }^{5}$ their physical characteristics and diagnoses are given in Table $I$. Some of these were selected because there was good reason, by clinical diagnosis, to suspect the existence of trapped gas, others were selected because there was no reason to suspect the presence of trapped gas. In each patient, three or more measurements of thoracic gas volume were made by the plethysmographic method (1) at the end of normal expiration; the average of these values is recorded in the tables. On the same day, with the patient in the same sitting position, duplicate measurements were made of the FRC by the dilution method of Darling, Cournand, and Richards (2). Duplicate determinations were required to check within 5 per cent except in some patients with emphysema in whom checks within 10 per cent were accepted. When the thoracic gas volume exceeded the volume measured by the dilution method by a significant amount ${ }^{6}$ (more than $0.44 \mathrm{~L}$. [1]) gas trapping was considered to be present. The respiratory minute volume was recorded during the sevenminute "washout" period, and the $\mathrm{N}_{2}$ concentration of inspired and expired gas was recorded continuously by a nitrogen meter with its sampling needle just outside the patient's lips. In addition, the following tests were performed on each patient: spirographic tracings of vital capacity (VC) and its subdivisions so that residual volume (RV) and total lung capacity (TLC) could be calculated, the single breath test of uneven distribution of inspired gas (3), the pulmonary $\mathrm{N}_{2}$ emptying rate (4), the maximal inspiratory and expiratory flow rates $(5,6)$ and the volume of gas in the abdominal cavity (7).

\section{RESULTS}

For the purposes of discussion, the patients have been divided into three groups: (A) those known

5 We wish to thank the medical and surgical staffs of the Hospital of the University of Pennsylvania for making these patients available to us for study.

B In a group of normal individuals the mean difference between the two methods was $0.0 \mathrm{~L}$., the S.D. of the differences between the two volumes was 0.22 L.; 2 S.D. equal $0.44 \mathrm{~L}$. 
by clinical or radiological studies to have air in pulmonary cysts or in a pneumothorax, (B) patients with pulmonary emphysema, and (C) patients with miscellaneous diseases; many of these were selected because they had cardiopulmonary disorders in which no non-ventilated areas were thought to exist.

\section{A. Patients believed to have trapped gas in the thorax}

This group included two patients with pulmonary cysts, three with combined emphysema and cysts and one with spontaneous pneumothorax (Table I). In each case, the thoracic gas volume measured by the plethysmographic technique was significantly greater than the FRC measured by the dilution method, the greatest difference being recorded in $\mathrm{E}$. S. in whom the gas volume measured plethysmographically was 7.37 L., actually double the seven-minute $\mathrm{N}_{2}$ washout space of 3.70 L. The mean thoracic gas volume in the six patients was $5.22 \mathrm{~L}$. and the mean FRC, as measured by the dilution method, 3.39 liters; the difference of 1.83 liters (standard error 0.48 ) is highly significant statistically.

\section{B. Patients with pulmonary emphysema}

These patients were 11 men, aged 47 to 81 years (Table I), diagnosed by clinical tests; their pulmonary function tests were compatible with this diagnosis. Nine of the 11 patients had a significant amount of trapped gas, i.e., the thoracic gas volume exceeded the FRC measured by the dilution method by more than 0.44 liters. The mean difference for the group was 1.09 liters (standard error 0.22).

\section{Patients with miscellaneous diseases}

This group included 19 patients with a wide variety of cardiopulmonary or thoracic abnormalities. Only four patients had a significant volume of trapped gas; it is of interest that all three patients with intrathoracic tumors had significant amounts of trapped gas. A fourth patient, R. H., is of special interest. He complained of shortness of breath on exertion and pain in the right hemithorax after a deep breath. He had reduced breath sounds over the right lung, and radiological study revealed increased radiolucency of the right lung without evidence of a cyst wall. Angiocardi- ography showed diminished blood flow to the right lung such as might occur in the absence of the right pulmonary artery. Bronchospirometry showed an essentially non-ventilating right lung with negligible gas exchange, and spirographic evidence of gas retained after a maximal inspiration. The thoracic gas volume was 1.51 liters greater than the FRC measured by the dilution technique. The comparison of the two methods in this man helped to establish the fact that the basic physiological alterations were trapping of gas and pulmonary vascular obliteration, i.e., obstructive emphysema of the right lung. Although the etiology of this was undetermined, the case is included to illustrate the principle that severe regional obstruction and distension of a part of the lungs may be disabling to the patient but not produce marked changes in the usual gross tests of pulmonary function. The usual tests measure only the function of those parts of the lungs which are in communication with the airway.

It is important to note that not all patients with pulmonary disease have a significant volume of trapped gas; this study indicates that in some disorders of the lung (such as pulmonary vascular sclerosis and certain types of pulmonary fibrosis) there may be little or no trapped gas even though cardiopulmonary function may be impaired seriously.

\section{DISCUSSION}

The plethysmographic method measures the volume of compressible gas within the thorax; this volume should include any gas in the pleural cavity (if there is a pneumothorax), gas in the esophagus (which is assumed to be a negligible quantity) and gas in the lungs. The last includes (a) gas in well ventilated portions of the lung, (b) gas in poorly ventilated portions, and (c) gas in areas whose communication with the airway is sufficiently closed to prevent tidal ventilation. The dilution methods for measuring lung volume certainly measure the volume of gas in the well ventilated regions of the lung and usually measure the volume of gas in the poorly ventilated areas as well. However, in some patients, the seven-minute open system test using $\mathrm{O}_{2}$ may not measure accurately the volume of gas in the poorly ventilated areas. Some of the evidence for this is 1) the $\mathrm{N}_{2}$ concentration of gas forcibly expelled from 
TABLE I

Measurements on 36 patients, to compare the volume of trapped gas (thoracic gas volume

\begin{tabular}{|c|c|c|c|c|c|c|c|c|c|c|}
\hline \multirow[b]{2}{*}{ Group } & \multirow[b]{2}{*}{ Patient } & \multirow[b]{2}{*}{ Diagnosis } & \multirow[b]{2}{*}{$\begin{array}{l}\text { Age } \\
\text { and } \\
\text { sex }\end{array}$} & \multirow[b]{2}{*}{$\begin{array}{l}\text { Height } \\
\text { (ix.) }\end{array}$} & \multirow[b]{2}{*}{$\begin{array}{l}\text { Weight } \\
(l b s .)\end{array}$} & \multirow[b]{2}{*}{$\underset{\left(M^{2}\right)}{\text { S.A. }}$} & \multirow[b]{2}{*}{$\begin{array}{l}\text { V.C. } \\
\text { (i. })\end{array}$} & \multirow[b]{2}{*}{$\begin{array}{c}\text { Min. } \\
\text { vol. } \\
\text { (L./min.) }\end{array}$} & \multicolumn{2}{|c|}{$\begin{array}{l}\text { Distribution of } \\
\text { inspired gas }\end{array}$} \\
\hline & & & & & & & & & $\begin{array}{l}\text { Single } \\
\text { breath } \\
\text { test } \\
\left(\% N_{2}\right)\end{array}$ & $\begin{array}{c}\text { Pulm. } N_{2} \\
\text { emptying } \\
\text { rate } \\
\left(\% N_{2}\right)\end{array}$ \\
\hline $\begin{array}{l}\mathbf{A} \\
\mathbf{A} \\
\mathbf{A} \\
\mathbf{A} \\
\mathbf{A} \\
\mathbf{A}\end{array}$ & $\begin{array}{l}\text { M. W. } \\
\text { R. C. } \\
\text { C. C. } \\
\text { G. B. } \\
\text { W. E. } \\
\text { E. S. }\end{array}$ & $\begin{array}{l}\text { Spontaneous Pneumothorax } \\
\text { Cysts of the lung } \\
\text { Cysts of the lung } \\
\text { Emphysema with cysts } \\
\text { Emphysema with cysts } \\
\text { Emphysema with cysts }\end{array}$ & $\begin{array}{l}28 M \\
30 M \\
27 M \\
55 M \\
57 M \\
49 M\end{array}$ & $\begin{array}{l}67 \\
63 \\
73 \\
65 \\
65 \\
66\end{array}$ & $\begin{array}{l}136 \\
154 \\
142 \\
152 \\
101 \\
110\end{array}$ & $\begin{array}{l}1.72 \\
1.73 \\
1.84 \\
1.77 \\
1.46 \\
1.55\end{array}$ & $\begin{array}{l}3.900 \\
3.200 \\
3.750 \\
1.900 \\
1.760 \\
1.880\end{array}$ & $\begin{array}{r}10.0 \\
12.1 \\
12.4 \\
9.1 \\
11.9 \\
8.0\end{array}$ & $\begin{array}{r}1.8 \\
1.7 \\
4.4 \\
12.1 \\
13.6 \\
7.5\end{array}$ & $\begin{array}{l}0.1 \\
0.1 \\
5.8 \\
3.2 \\
1.7 \\
3.3\end{array}$ \\
\hline \multirow{2}{*}{$\begin{array}{l}\mathbf{B} \\
\mathbf{B} \\
\mathbf{B} \\
\mathbf{B} \\
\mathbf{B} \\
\mathbf{B} \\
\mathbf{B} \\
\mathbf{B} \\
\mathbf{B} \\
\mathbf{B}\end{array}$} & $\begin{array}{l}\text { C. P. } \\
\text { H. B. } \\
\text { R. C. } \\
\text { J. D. }\end{array}$ & \multirow{3}{*}{$\begin{array}{l}\text { Emphysema } \\
\text { Emphysema } \\
\text { Emphysema } \\
\text { Emphysema with cor pul- } \\
\text { monale } \\
\text { Emphysema } \\
\text { Emphysema } \\
\text { Emphysema } \\
\text { Emphysema with fibrosis } \\
\text { Emphysema } \\
\text { Emphysema with pleural } \\
\text { effusion } \\
\text { Emphysema }\end{array}$} & $\begin{array}{l}64 \mathrm{M} \\
59 \mathrm{M} \\
55 \mathrm{M}\end{array}$ & $\begin{array}{l}68 \\
67 \\
70\end{array}$ & $\begin{array}{l}116 \\
119 \\
165\end{array}$ & $\begin{array}{l}1.62 \\
1.60 \\
1.96\end{array}$ & $\begin{array}{l}2.820 \\
2.360 \\
3.260\end{array}$ & $\begin{array}{l}9.3 \\
9.1 \\
9.7\end{array}$ & $\begin{array}{r}10.7 \\
13.7 \\
6.4\end{array}$ & $\begin{array}{l}6.1 \\
5.5 \\
2.2\end{array}$ \\
\hline & $\begin{array}{l}\text { G. G. } \\
\text { C. K. } \\
\text { M. M. } \\
\text { R. P. } \\
\text { W. M. } \\
\text { A. P. }\end{array}$ & & $\begin{array}{l}57 \mathrm{M} \\
55 \mathrm{M} \\
47 \mathrm{M} \\
69 \mathrm{M} \\
57 \mathrm{M} \\
75 \mathrm{M}\end{array}$ & $\begin{array}{l}69 \\
71 \\
67 \\
65 \\
65 \\
67\end{array}$ & $\begin{array}{l}122 \\
158 \\
165 \\
105 \\
146 \\
163\end{array}$ & $\begin{array}{l}1.68 \\
1.91 \\
1.86 \\
1.50 \\
1.75 \\
1.86\end{array}$ & $\begin{array}{l}2.000 \\
2.840 \\
2.675 \\
2.620 \\
4.450 \\
2.980\end{array}$ & $\begin{array}{r}10.2 \\
12.3 \\
9.8 \\
7.2 \\
12.7 \\
10.0\end{array}$ & $\begin{array}{r}7.0 \\
12.2 \\
5.2 \\
4.6 \\
5.5 \\
3.5\end{array}$ & $\begin{array}{l}5.7 \\
6.2 \\
1.1 \\
2.0 \\
0.8 \\
1.0\end{array}$ \\
\hline B & R. N. & & $\begin{array}{l}81 \mathrm{M} \\
55 \mathrm{M}\end{array}$ & $\begin{array}{l}66 \\
66\end{array}$ & $\begin{array}{l}117 \\
157\end{array}$ & $\begin{array}{l}1.59 \\
1.82\end{array}$ & $\begin{array}{l}1.440 \\
2.650\end{array}$ & $\begin{array}{r}7.3 \\
11.2\end{array}$ & $\begin{array}{l}5.5 \\
9.0\end{array}$ & $\begin{array}{l}1.5 \\
2.0\end{array}$ \\
\hline \multirow[t]{2}{*}{ 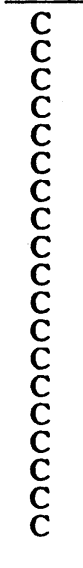 } & \multirow[t]{2}{*}{$\begin{array}{l}\text { T. C. } \\
\text { R. H. } \\
\text { E. B. } \\
\text { J. H. } \\
\text { H. G. } \\
\text { C. S. } \\
\text { R. G. } \\
\text { H. W. } \\
\text { C. M. } \\
\text { M. H. } \\
\text { E. Z. } \\
\text { R. D. } \\
\text { A. S. } \\
\text { I. M. } \\
\text { R. M. } \\
\text { L. H. } \\
\text { J. K. } \\
\text { G. T. } \\
\text { R. K. }\end{array}$} & \multirow[t]{2}{*}{$\begin{array}{l}\text { Chemical burns of lungs } \\
\text { Emphysema right lung } \\
\text { Kyphoscoliosis } \\
\text { Kyphoscoliosis } \\
\text { Kyphoscoliosis } \\
\text { Kyphoscoliosis } \\
\text { Fibromas of lung } \\
\text { Carcinoma of L.L.L. } \\
\text { Mediastinal mass } \\
\text { Diffuse interstitial fibrosis } \\
\text { Diffuse interstitial fibrosis } \\
\text { Scleroderma } \\
\text { Boeck's sarcoid } \\
\text { Pulm. arteriosclerosis } \\
\text { Pulm. arteriosclerosis } \\
\text { Pulm. arteriosclerosis } \\
\text { Hemosiderosis of lungs } \\
\text { Rheumatic heart disease } \\
2 \text { previous spontaneous } \\
\text { pneumothorax }\end{array}$} & $\begin{array}{l}30 \mathrm{M} \\
28 \mathrm{M} \\
17 \mathrm{~F} \\
30 \mathrm{M} \\
39 \mathrm{~F} \\
46 \mathrm{~F} \\
45 \mathrm{~F} \\
52 \mathrm{M} \\
50 \mathrm{M} \\
52 \mathrm{~F} \\
16 \mathrm{M} \\
45 \mathrm{M} \\
53 \mathrm{M} \\
44 \mathrm{~F} \\
15 \mathrm{M} \\
28 \mathrm{M} \\
31 \mathrm{M} \\
28 \mathrm{M}\end{array}$ & $\begin{array}{l}72 \\
66 \\
55 \\
61 \\
53 \\
50 \\
64 \\
66 \\
65 \\
67 \\
69 \\
61 \\
62 \\
62 \\
65 \\
69 \\
72 \\
70\end{array}$ & $\begin{array}{r}162 \\
135 \\
111 \\
102 \\
97 \\
99 \\
113 \\
135 \\
136 \\
154 \\
157 \\
96 \\
119 \\
106 \\
101 \\
152 \\
170 \\
137\end{array}$ & $\begin{array}{l}1.95 \\
1.69 \\
1.58 \\
1.41 \\
1.26 \\
1.22 \\
1.53 \\
1.70 \\
1.67 \\
1.81 \\
1.86 \\
1.37 \\
1.53 \\
1.46 \\
1.50 \\
1.83 \\
1.97 \\
1.80\end{array}$ & $\begin{array}{l}3.250 \\
2.000 \\
1.920 \\
1.050 \\
2.300 \\
.950 \\
1.990 \\
2.480 \\
3.880 \\
1.500 \\
1.145 \\
1.780 \\
2.860 \\
2.760 \\
2.050 \\
5.050 \\
4.150 \\
3.300\end{array}$ & $\begin{array}{r}10.1 \\
13.7 \\
12.5 \\
8.6 \\
6.8 \\
5.7 \\
7.5 \\
10.0 \\
\\
9.8 \\
12.9 \\
10.8 \\
12.5 \\
12.8 \\
13.2 \\
11.9 \\
11.8 \\
10.4\end{array}$ & $\begin{array}{l}2.7 \\
2.0 \\
6.4 \\
\dagger \\
2.7 \\
\dagger \\
2.2 \\
1.7 \\
1.2 \\
9.7 \\
\dagger \\
5.7 \\
8.1 \\
0.5 \\
1.7 \\
3.2 \\
1.0 \\
2.5\end{array}$ & $\begin{array}{l}0.5 \\
3.3 \\
0.3 \\
0.3 \\
0.1 \\
0.2 \\
1.8 \\
1.0 \\
0.5 \\
0.2 \\
0.2 \\
0.2 \\
0.3 \\
0.2 \\
0.2 \\
0.5 \\
0.7 \\
0.4\end{array}$ \\
\hline & & & $25 \mathrm{M}$ & 72 & 140 & 1.83 & 5.030 & 10.6 & 2.0 & 0.2 \\
\hline
\end{tabular}

${ }^{*}$ S.A. = Body surface area, V.C. $=$ Vital capacity, Min. Vol. $=$ Minute volume of respiration, FRC $=$ Functional residual capacity, $\mathrm{RV}=$ Residual volume, $\mathrm{TLC}=$ Total lung capacity.

$\dagger$ Insufficient volume.

the lungs at the end of a seven-minute period may be abnormally high, but not representative of the $\mathrm{N}_{2}$ concentration of the gas remaining in the lungs $(4), 2)$ in some patients, the gas space measured over a 10 to 12 -minute period may be greater than that measured over a seven-minute period $(2,8)$, 3 ) the gas space measured by clearance curves following prolonged inhalation of 50 per cent $\mathrm{O}_{2}$ and 50 per cent helium is occasionally greater in emphysematous patients than the gas space measured by the pulmonary $\mathrm{N}_{2}$ clearance technique (9). The dilution methods, whether measuring $\mathrm{He}$ or $\mathrm{N}_{2}$ washout, cannot of course measure the volume of gas in alveoli with completely closed airways at the time of the test.

The plethysmographic technique at the present time is the only method available for detecting the existence and measuring the volume of gas not included in the dilution methods for measuring FRC. Other methods which have been used to suggest the presence of gas trapping or to measure the quantity of gas trapped include 1) radiologic estimation of unchanging radiolucency or volume of the lung fields during normal or forced 
VOLUME OF GAS TRAPPED IN THE LUNGS

TABLE I-Continued

minus functional residual capacity) with other clinical and physiological findings*

\begin{tabular}{|c|c|c|c|c|c|c|c|c|c|c|c|}
\hline \multirow[b]{2}{*}{$\begin{array}{c}\text { Max. exp. } \\
\text { flow rate } \\
200-1,200 \mathrm{ml} . \\
(L . / \min .)\end{array}$} & \multirow[b]{2}{*}{$\begin{array}{c}\text { Max. insp. } \\
\text { flow rate } \\
200-1,200 \mathrm{ml} . \\
(L . / \text { mix. })\end{array}$} & \multicolumn{4}{|c|}{ Dilution method } & \multicolumn{4}{|c|}{ Plethysmographic method } & \multirow{2}{*}{ 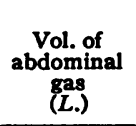 } & \multirow{2}{*}{$\begin{array}{c}\text { Thoracic } \\
\text { gas } \\
\text { volume- } \\
\text { FRC } \\
(L .)\end{array}$} \\
\hline & & FRC & $\mathbf{R V}$ & TLC & $\begin{array}{l}\text { RV/ } \\
\text { TLC } \\
(\%)\end{array}$ & $\begin{array}{c}\text { Thor. } \\
\text { gas } \\
\text { vol. }\end{array}$ & $\mathbf{R V}$ & TLC & $\begin{array}{l}\text { RV/ } \\
\text { TLC } \\
(\%)\end{array}$ & & \\
\hline $\begin{array}{r}400 \\
215 \\
210 \\
13 \\
28 \\
18\end{array}$ & $\begin{array}{l}270 \\
120 \\
165 \\
270 \\
220 \\
100\end{array}$ & $\begin{array}{l}2.62 \\
2.30 \\
3.52 \\
4.92 \\
3.30 \\
3.70\end{array}$ & $\begin{array}{l}1.48 \\
1.32 \\
2.02 \\
4.33 \\
2.72 \\
3.07\end{array}$ & $\begin{array}{l}5.38 \\
4.52 \\
5.77 \\
6.23 \\
4.48 \\
4.95\end{array}$ & $\begin{array}{l}27 \\
29 \\
35 \\
70 \\
61 \\
62\end{array}$ & $\begin{array}{l}3.44 \\
2.93 \\
4.65 \\
7.51 \\
5.43 \\
7.37\end{array}$ & $\begin{array}{l}2.30 \\
1.95 \\
3.15 \\
6.92 \\
4.85 \\
6.74\end{array}$ & $\begin{array}{l}6.20 \\
5.15 \\
6.90 \\
8.82 \\
6.61 \\
8.62\end{array}$ & $\begin{array}{l}37 \\
38 \\
46 \\
78 \\
73 \\
78\end{array}$ & $\begin{array}{l}0.233 \\
0.000\end{array}$ & $\begin{array}{l}0.82 \\
0.63 \\
1.13 \\
2.59 \\
2.13 \\
3.67\end{array}$ \\
\hline $\begin{array}{r}50 \\
15 \\
105\end{array}$ & $\begin{array}{l}140 \\
115 \\
170\end{array}$ & $\begin{array}{l}5.87 \\
4.57 \\
5.28\end{array}$ & $\begin{array}{l}4.46 \\
3.49 \\
3.86\end{array}$ & $\begin{array}{l}7.28 \\
5.85 \\
7.06\end{array}$ & $\begin{array}{l}61 \\
60 \\
55\end{array}$ & $\begin{array}{l}7.72 \\
6.12 \\
6.04\end{array}$ & $\begin{array}{l}6.31 \\
5.04 \\
4.62\end{array}$ & $\begin{array}{l}9.13 \\
7.40 \\
7.88\end{array}$ & $\begin{array}{l}69 \\
68 \\
59\end{array}$ & $\begin{array}{l}0.000 \\
0.171 \\
0.134\end{array}$ & $\begin{array}{l}1.85 \\
1.55 \\
0.76\end{array}$ \\
\hline $\begin{array}{r}15 \\
37 \\
50 \\
150 \\
68 \\
50\end{array}$ & $\begin{array}{l}150 \\
120 \\
280 \\
310 \\
147 \\
220\end{array}$ & $\begin{array}{l}5.46 \\
5.33 \\
3.88 \\
2.98 \\
5.17 \\
4.08\end{array}$ & $\begin{array}{l}4.54 \\
3.99 \\
3.20 \\
1.86 \\
3.05 \\
2.87\end{array}$ & $\begin{array}{l}6.54 \\
6.83 \\
5.87 \\
4.48 \\
7.50 \\
5.85\end{array}$ & $\begin{array}{l}69 \\
58 \\
55 \\
42 \\
41 \\
49\end{array}$ & $\begin{array}{l}7.84 \\
6.46 \\
3.76 \\
3.18 \\
6.80 \\
4.97\end{array}$ & $\begin{array}{l}6.92 \\
5.12 \\
3.08 \\
2.06 \\
4.68 \\
3.76\end{array}$ & $\begin{array}{l}8.92 \\
7.96 \\
5.76 \\
4.68 \\
9.13 \\
6.74\end{array}$ & $\begin{array}{l}78 \\
64 \\
54 \\
44 \\
51 \\
56\end{array}$ & 0.000 & $\begin{array}{r}2.38 \\
1.13 \\
-0.12 \\
0.20 \\
1.63 \\
0.89\end{array}$ \\
\hline $\begin{array}{l}10 \\
26\end{array}$ & $\begin{array}{r}76 \\
170\end{array}$ & $\begin{array}{l}2.89 \\
4.28\end{array}$ & $\begin{array}{l}2.27 \\
3.29\end{array}$ & $\begin{array}{l}3.81 \\
5.94\end{array}$ & $\begin{array}{l}60 \\
55\end{array}$ & $\begin{array}{l}3.87 \\
4.97\end{array}$ & $\begin{array}{l}3.25 \\
3.98\end{array}$ & $\begin{array}{l}4.69 \\
6.63\end{array}$ & $\begin{array}{l}69 \\
60\end{array}$ & 0.221 & $\begin{array}{l}0.98 \\
0.69\end{array}$ \\
\hline $\begin{array}{c}115 \\
76 \\
122 \\
77 \ddagger \\
215 \\
44 \ddagger \\
67 \\
150 \\
325 \\
210 \\
230 \ddagger \\
430 \\
200 \\
160 \\
140 \\
300 \\
600 \\
300\end{array}$ & $\begin{array}{c}130 \\
122 \\
140 \\
75 \ddagger \\
135 \\
89 \ddagger \\
130 \\
220 \\
180 \\
158 \\
240 \ddagger \\
250 \\
170 \\
140 \\
250 \\
225 \\
370 \\
270\end{array}$ & $\begin{array}{l}3.31 \\
2.61 \\
1.30 \\
1.28 \\
1.69 \\
1.00 \\
2.78 \\
2.23 \\
2.95 \\
1.25 \\
2.37 \\
1.61 \\
2.85 \\
2.57 \\
1.99 \\
3.72 \\
2.90 \\
2.58\end{array}$ & $\begin{array}{l}2.30 \\
1.73 \\
1.03 \\
0.85 \\
1.16 \\
0.74 \\
2.36 \\
1.48 \\
1.67 \\
0.69 \\
1.77 \\
0.80 \\
1.49 \\
1.45 \\
1.33 \\
1.72 \\
1.85 \\
1.60\end{array}$ & $\begin{array}{l}5.55 \\
3.73 \\
2.95 \\
1.90 \\
3.46 \\
1.69 \\
4.35 \\
3.96 \\
5.55 \\
2.19 \\
2.91 \\
2.58 \\
4.35 \\
4.21 \\
3.38 \\
6.77 \\
6.00 \\
4.90\end{array}$ & $\begin{array}{l}41 \\
46 \\
35 \\
45 \\
34 \\
44 \\
54 \\
37 \\
30 \\
31 \\
61 \\
31 \\
34 \\
34 \\
39 \\
25 \\
31 \\
33\end{array}$ & $\begin{array}{l}3.49 \\
3.97 \\
1.45 \\
1.19 \\
2.04 \\
1.38 \\
3.40 \\
2.98 \\
3.47 \\
1.38 \\
2.12 \\
1.33 \\
2.73 \\
2.66 \\
1.96 \\
4.08 \\
3.14 \\
2.75\end{array}$ & $\begin{array}{l}2.48 \\
3.09 \\
1.18 \\
0.76 \\
1.51 \\
1.12 \\
2.98 \\
2.23 \\
2.19 \\
0.82 \\
1.52 \\
0.52 \\
1.37 \\
1.54 \\
1.30 \\
2.08 \\
2.09 \\
1.77\end{array}$ & $\begin{array}{l}5.73 \\
5.09 \\
3.10 \\
1.81 \\
3.81 \\
2.07 \\
4.97 \\
4.71 \\
6.07 \\
2.32 \\
2.67 \\
2.30 \\
4.23 \\
4.30 \\
3.35 \\
7.13 \\
6.24 \\
5.07\end{array}$ & $\begin{array}{l}43 \\
61 \\
39 \\
42 \\
40 \\
54 \\
60 \\
47 \\
34 \\
35 \\
57 \\
23 \\
32 \\
36 \\
39 \\
29 \\
33 \\
35\end{array}$ & $\begin{array}{l}0.375 \\
0.000 \\
\\
0.013 \\
0.056 \\
0.107 \\
\\
0.118 \\
0.000 \\
0.092 \\
0.000 \\
0.174 \\
0.156 \\
0.090 \\
0.186\end{array}$ & $\begin{array}{r}0.18 \\
1.36 \\
0.15 \\
-0.09 \\
0.35 \\
0.38 \\
0.62 \\
0.75 \\
0.52 \\
0.13 \\
-0.25 \\
-0.28 \\
-0.12 \\
0.11 \\
-0.03 \\
0.36 \\
0.24 \\
0.17\end{array}$ \\
\hline 600 & 300 & 4.41 & 2.58 & 7.61 & 34 & 4.65 & 2.82 & 7.85 & 36 & & 0.24 \\
\hline
\end{tabular}

$\ddagger$ Measured over 200 - to 700 -ml. range.

breathing 2) radiologic measurement of increased chest volume in patients with a normal FRC measured by dilution techniques $(10-12), 3)$ the finding of a variable end-expiratory level in spirograms recorded during normal breathing or following a deep inspiration, 4) marked variability of the FRC on repeated determinations by the gas washout methods, and 5) the finding of a high $\mathrm{N}_{2}$ concentration in the gas sample expelled from the lung by forced expiration after a period of $\mathrm{O}_{2}$ inhalation of seven minutes (4). All of these tests suggest that gas trapping exists to a certain extent but give no measure of the actual magnitude.
The measurements on the patients in group A serve to prove that the present method is capable of determining the presence of a volume of trapped gas. Patient M. W. had a spontaneous pneumothorax with radiologic evidence of gas in the pleural cavity; at this time, the thoracic gas volume, measured plethysmographically, exceeded by 0.82 liters the FRC measured by the dilution method. Part of this volume was in the pleural space, but part may also have been present in cysts or blebs not visible by $\mathrm{X}$-ray. It should be possible to determine the latter after reabsorption of the pneumothorax. The patients with well defined 
cysts also had significant amounts of trapped gas, indicating that at least part of the cysts were not ventilated, the volumes being in the range expected from the radiologic examination.

It is of interest that in two of the five patients with cysts, the concentration of $\mathrm{N}_{2}$ in the expired alveolar gas after seven minutes of $\mathrm{O}_{2}$ inhalation was normal; in these two, the openings of the cysts must have been completely occluded at the time of the test. In the other three, the concentration of expired alveolar $\mathrm{N}_{2}$ was high, suggesting either that some gas could be expelled from all of the cysts by forced expiration or that some cysts or regions were poorly ventilated while other cysts or regions were closed at that time.

The measurements on patients with emphysema (group B) are of great interest. First, they confirm the suspicion of Cournand, Baldwin, Darling, and Richards (4) that either the orifices to some alveoli are completely closed to outflow or that many alveoli are so poorly ventilated that the dilution method greatly underestimates the volume of their contained gas. The average volume of trapped gas in the 11 patients was 1.09 liters; in only 2 of the 11 patients was there no significant volume of trapped gas.

Second, they confirm the statement of Darling, Cournand, and Richards (2) that the total lung capacity of patients with emphysema is often much too low as measured by the seven-minute method. Although we have not had the opportunity to measure total lung capacity by the $\mathrm{He}-\mathrm{O}_{2}$ method of Hickam, Blair, and Frayser (8), it is possible that our values, measured plethysmographically, might be higher than theirs on some of the same patients because our values for thoracic gas volume include trapped gas and non-ventilated gas as well as gas in poorly ventilated spaces. The thoracic gas volume in our 11 patients calculated for maximal inspiratory level varied from 4,690 to $9,130 \mathrm{ml}$. and all but three exceeded 110 per cent of the predicted values for total lung capacity for healthy men in their age group. In all probability, the estimation of absolute values and conclusions drawn from published values for RV, FRC, and TLC will have to be revised considerably in patients with emphysema. The RV/TLC ratio in such patients will also be subject to revision, though the increase in the ratio will be less than the increase in the absolute volumes of $R V$ and
TLC. Thus, the RV/TLC ratio of patient R. P. was $3.05 / 7.50$ or 41 per cent measured by the dilution method but $4.68 / 9.13$ or 51 per cent by the new method.

Third, the $\mathrm{N}_{2}$ concentration in the alveolar gas sample obtained by forced expiration after seven minutes inhalation of $\mathrm{O}_{2}$ gives no certain information regarding the presence or amount of trapped gas. If the $\mathrm{N}_{2}$ concentration in the expired alveolar gas is high on forced expiration, some regions must have been non- or poorly-ventilated during quiet breathing and in each of these cases trapped gas was found by the plethysmographic method. However, in four of the 11 patients with emphysema, the $\mathrm{N}_{2}$ concentration was within normal limits and yet there was a significant volume of trapped gas in each $(0.76,0.89,0.98$, and 1.63 liters). This suggests that, as in the case of cysts, there are some areas from which gas cannot be expelled by such a forced expiration; indeed in cases in which check valves exist (4), the forced expiration may even hinder the emptying of the region.

Fourth, a question is raised concerning the proper asymptote for analysis of nitrogen dilution curves. Although a certain part of the expired gas is commonly used as an asymptote for plotting the curves on semilogarithmic paper (13), a considerable quantity of nitrogen may remain undetected in the lungs, unrepresented in the dilution curve. Therefore the analysis of nitrogen in the expired gas does not necessarily permit estimation of the quantity of nitrogen remaining in the lungs, or the estimation of the volume of well ventilated and poorly ventilated regions, unless the quantity of gas remaining in the lungs is actually measurable, as it is in the plethysmographic method described above.

The measurements on patients in group $C$ have little significance at present because of the small number of patients in each group. It is of interest, however, to find that all three of our patients with intrapulmonary or intrathoracic tumors had trapped gas and that our patients with interstitial pulmonary fibrosis had none.

\section{Possible sources of error}

Several potential sources of error in the measurement of FRC by the dilution technique might have made these values too low in the patients 
with emphysema and so exaggerated the difference in volumes by the two methods:

1. If the patients had hypoventilated, the nitrogen might not have been washed out during the seven-minute period of $\mathrm{O}_{2}$ inhalation. However, the measured ventilatory volumes indicate that the patients actually were hyperventilating during the test period, and the final expired alveolar nitrogen concentration was less than 2.5 per cent at the end of the seven-minute period of oxygen breathing in six of the 11 patients; the latter observation indicates that the nitrogen in communication with airways open during forced expiration was washed out. Therefore, hypoventilation cannot explain the differences. The use, in calculation of FRC, of the actual figure for end-expired $\mathrm{N}_{2}$ concentration as a value representative of all alveolar gas is, of course, questionable, as pointed out by Cournand, Baldwin, Darling, and Richards (4).

The plethysmographic method measures the volume of compressible gas in the thorax regardless of ventilation rates or uniformity of ventilation and does not depend upon sampling of alveolar gas. When the thoracic gas volume was unusually high in any patient, the method was tested for systematic errors by measuring the thoracic gas volume in a staff member whose volume was known to be fairly constant from day to day.

\section{Phenomenon of gas trapping}

This has not been studied quantitatively in man in the past because of lack of methods for measuring the volume of trapped gas. There is of course evidence that air trapping does occur in man and can be produced in experimental animals. For example, in patients with status asthmaticus who come to autopsy, the lungs remain inflated even with positive external pressure applied manually. In such cases, the communications between alveoli and larger airways must be completely blocked by bronchiolar constriction, mucosal congestion or edema or by intraluminal secretions. Nisell produced a similar condition in the curarized cat by administration of carbaminocholine by aerosol (14); in this case, the respiration pump (positive pressure on inspiration only) was able to push air past obstructions in the airways into the alveoli during inspiration, but the elastic re- coil of the lungs was unable to expel the same volume during expiration. Roncoroni and Comroe, using different methods (15), made similar observations following thermal injury to the respiratory tract of the cat produced by inhalation of steam; again, air entered some alveoli but was unable to escape because of occlusion of the airways. Both Nisell and Roncoroni and Comroe also observed changes in lung compliance and non-elastic pulmonary resistance compatible with complete closure of part of the bronchial tree and partial closure of the remainder.

There is also little doubt that gas trapping occurs in many patients with emphysema. The "minimal air" volume of the lungs of patients with emphysema at autopsy is often increased even in the absence of obvious blebs or cysts. The increase in the resting expiratory level that occurs during life in such patients with rapid forced breathing (as in performing the maximal breathing capacity test) indicates that more gas enters than leaves the lungs, i.e., some gas may be trapped.

The inability of patients with emphysema to expire to a normal residual volume may be attributed either to loss of elasticity and stiffening of the thoracic cage in an expanded position ("nonobstructive emphysema") or to expiratory gas trapping ("obstructive emphysema"). In 'nonobstructive' emphysema, the residual volume should participate in gas dilution, should contribute $\mathrm{N}_{2}$ to a forced expiration at seven minutes, and there should not be increased expiratory resistance to airflow. By contrast, the present measurements indicate that in some patients with emphysema gas is trapped at certain times in the alveoli (even though this gas may partly exchange with inspired gas over a seven-minute test period). The present measurements provide for the first time a measure of the actual volume of gas so trapped and help to distinguish between non-obstructive emphysema and obstructive emphysema.

Some mechanisms by which gas may be trapped in the alveoli of patients with emphysema have been discussed by Dayman (16). Whatever the mechanism, the gas cannot be obstructed behind a permanently closed airway or absorption of gas by the blood and atelectasis would result. In all probability, the regions involved are intermittently 
in communication with the bronchioles; when a certain amount of gas is absorbed into the blood, the airway opens to admit more gas to the alveoli. If there were free communication and the tissues were compliant during both inspiration and expiration, the breathing of $\mathrm{O}_{2}$ should eventually eliminate $\mathrm{N}_{2}$ from the alveolar gas in these areas so that the volume of gas contained in these regions would be included in the FRC measured by the dilution methods.

\section{SUMMARY AND CONCLUSIONS}

The thoracic gas volume, which includes all the compressible gas in the lungs and thorax whether in communication with the airway or not, has been measured plethysmographically at the end of normal expiration in 36 patients with cardiopulmonary or thoracic disorders. The volume of gas in the lungs in communication with the airway was measured in the same patients by the dilution or "washout" method of Darling and associates. Thoracic gas volume minus "washout" volume is the volume of 'trapped' gas. In patients with pneumothorax, pulmonary cysts, emphysema and intrathoracic or pulmonary tumors (all conditions in which "trapping" of gas is known or thought to occur), the thoracic gas volume exceeded the "washout" volume by a significant amount (more than 0.44 liter); in one patient with pulmonary cysts and emphysema the excess volume (i.e., trapped gas volume) was 3.67 liters. In patients with other cardiopulmonary or thoracic disorders, no significant amount was found.

The combined use of these two methods for measuring gas volumes provides a method for studying the phenomenon of gas trapping and for extending our knowledge regarding true residual volume and total lung capacity in patients with certain types of pulmonary disease.

\section{REFERENCES}

1. DuBois, A. B., Botelho, S. Y., Bedell, G. N., Marshall, R., and Comroe, J. H., Jr., A rapid plethysmographic method for measuring thoracic gas volume: A comparison with the nitrogen washout method for measuring functional residual capacity in normal subjects. J. Clin. Invest., 1956, 35, 322.

2. Darling, R. C., Cournand, A., and Richards, D. W., Jr., Studies on the intrapulmonary mixture of gases. III. An open circuit method for measuring residual air. J. Clin. Invest., 1940, 19, 609.

3. Comroe, J. H., Jr., and Fowler, W. S., Lung function studies. VI. Detection of uneven alveolar ventilation during a single breath of oxygen. Am. J. Med., 1951, 10, 408.

4. Cournand, A., Baldwin, E. deF., Darling, R. C., and Richards, D. W., Jr., Studies on intrapulmonary mixture of gases. IV. The significance of the pulmonary emptying rate and a simplified open circuit measurement of residual air. J. Clin. Invest., 1941, 20, 681.

5. Danzig, L., and Comroe, J. H., Jr., A critical analysis of rapid spirographic techniques. In preparation.

6. Cander, L., and Comroe, J. H., Jr., A method for the objective evaluation of bronchodilator drugs. Effects of dapanone, isuprel, and aminophylline in patients with bronchial asthma. J. Allergy, 1955, 26, 210.

7. Bedell, G. N., Marshall, R., DuBois, A. B., and Harris, J. H., Measurement of the volume of gas in the gastro-intestinal tract. Values in normal subjects and ambulatory patients. J. Clin. Invest., 1956, 35, 336.

8. Hickam, J. B., Blair, E., and Frayser, R., An opencircuit helium method for measuring functional residual capacity and defective intrapulmonary gas mixing. J. Clin. Invest., 1954, 33, 1277.

9. Hickam, J., and Frayser, R., A comparative study of intrapulmonary gas mixing and functional residual capacity in pulmonary emphysema, using helium and nitrogen as the test gases. Abstracts, J. Clin. Invest., 1955, 34, 917.

10. Hurtado, A., Fray, W. W., and McCann, W. S., Studies of total pulmonary capacity and its subdivisions. IV. Preliminary observations on cases of pulmonary emphysema and of pneumoconiosis. J. Clin. Invest., 1933, 12, 833.

11. Baldwin, E. deF., Harden, K. A., Greene, D. G., Cournand, A., and Richards, D. W., Jr., Pulmonary insufficiency. IV. A study of 16 cases of large pulmonary air cysts or bullae. Medicine, 1950, 29, 169.

12. Harden, K. A., Pulmonary air cysts: Some diagnostic, physiologic and therapeutic considerations. J. Nat. M. A., 1953, 45, 167.

13. Fowler, W. S., Cornish, E. R., Jr., and Kety, S. S., Lung function studies. VIII. Analysis of alveolar ventilation by pulmonary $\mathrm{N}_{2}$ clearance curves. J. Clin. Invest., 1952, 31, 40.

14. Nisell, O. I., Unpublished data.

15. Roncoroni, A., and Comroe, J. H., Jr., Unpublished data.

16. Dayman, H., Mechanics of airflow in health and in emphysema. J. Clin. Invest., 1951, 30, 1175. 